Volume. 4 Nomor. 1

Periode: Januari - Juni 2020; hal. 22-27

p-ISSN : 2580-1112; e-ISSN : 2655-6669

Copyrighr@2020

Penulis memiliki hak cipta atas artikel ini

journal homepage: https://ejournal.akperfatmawati.ac.id

DOI: $10.46749 / \mathrm{jiko.v3i2.36}$
Jurnal Ilmiah Keperawatan Orthopedi (JIKO)

Article history:

Received: Desember 12, 19

Revised: September 04, 20

Accepted: September 09, 20

\title{
Peranan Electronic Health Record System terhadap Keselamatan Pasien di Perawatan Anak
}

\author{
Yayah $^{1}$, La Ode Abdul Rahman ${ }^{2}$ \\ Fakultas Ilmu Keperawatan Universitas Indonesia, Depok
}

\begin{abstract}
Abstrak
EHRs merupakan bentuk perkembangan teknologi informasi berupa sistem dokumentasi kesehatan dalam format digital yang dapat memberikan tampilan data otomatis yang mendukung dalam kelengkapan dan keakuratan data yang diharapkan dapat meningkatkan keselamatan pasien termasuk di perawatan anak. Karena anak merupakan populasi yang rentan dalam isu keselamatan pasien. Tujuan penelitian ini adalah untuk mengetahui peranan EHRs terkait keselamatan pasien di perawatan anak. Penelitian ini menggunakan studi literatur dengan melakukan kajian artikel dan jurnal penelitian yang dicari melalui penelusuran database online yang terbit tahun 2014-2019 dengan kata kunci "electronic health record" OR "electronic medical record" AND "pediatric" AND "patient safety" sebanyak 10 artikel dijadikan bahan analisis utama ditambahkan artikel lainnya sebagai sebagai pendukung pembahasan. Hasil penelitian ini menunjukan bahwa EHRs yang sudah dimodifikasi dengan menampilkan umpan balik tanda waspada berupa sistem peringatan dengan tampilan visual dapat meningkatkan komunikasi yang efektif antar tim kesehatan, memberikan peringatan dalam keamanan dan kewaspadaan obat, serta deteksi dini sepsis pada anak sehingga mendukung pengambilan keputusan untuk melakukan tindakan yang tepat untuk meningkatkan keselamatan pasien. EHRs yang sudah dimodifikasi dengan sistem pendukung berupa sistem peringatan memiliki peranan positif dan efektif dalam meningkatkan keselamatan pasien di perawatan anak.
\end{abstract}

Kata Kunci: Electronic Health Record System, Keselamatan Pasien, Perawatan Anak

\begin{abstract}
EHRs are a form of development information technology in the digital health documentation system in which format that can provide automatic data display that supports the completeness and accuracy of data. ERHs expected to improve patient safety, including in pediatric nursing care rooms because children are a vulnerable population issue of patient safety. Aim of this study is to find the role of ERHs related to patient safety in pediatric nursing care. In this research use literature study by analyzed research articles and journals search an online database published in 2014-2019 with the keywords "Electronic Health Record" OR "Electronic Medical Record" AND "Paediatric" AND "Patient Safety", 10 articles used as the main analysis material is added by other articles as supporting discussion. The result showed modified EHRs by displaying alerts in the form of a warning system with a visual display can improve effective communication between health teams, provide warnings in drug safety and alertness, early detection of sepsis in children support decision making to take appropriate actions and right to improve patient safety. EHRs that have been modified with a support system in the form of a warning system has a positive and effective role in improving patient safety in the pediatric care room.
\end{abstract}

\footnotetext{
1,2 e-mail: yayah.3479@gmail.com
} 
Keyword: Electronic Health Record System, Patient Safety, Pediatric Care

\section{Pendainuiual}

Perkembangan teknologi semakin pesat seiring dengan kemajuan teknologi Era Industri 4.0 dengan ketersediaan semua informasi yang relevan secara otomatis, kemampuan yang optimal untuk memperoleh hasil dari setiap data yang penting (Koch, Kuge, Geissbauer, \& Schrauf, 2014). Perkembangan teknologi ini juga dimanfaatkan di rumah sakit dalam bentuk catatan kesehatan elektronik atau electronic health record system (EHRs).

EHRs dapat didefinisikan sebagai Catatan kesehatan elektronik yang berisi catatan detail mengenai data kesehatan pasien termasuk riwayat, pemeriksaan fisik, investigasi, dan perawatan dalam format digital yang menawarkan beberapa keuntungan lebih dari catatan kertas (Jamshed, Ozair, Sharma, \& Aggarwal, 2015). EHRs dapat menghilangkan masalah dokumentasi yang tidak terbaca, memberikan pemahaman yang lebih luas tentang status kesehatan pasien, dengan dukungan sistem otomatis (King, Patel, Jamoom, \& Furukawa, 2014).

EHRs memberikan kemudahan dengan sistem yang mendukung kelengkapan dan keakuratan data termasuk memberi tanda waspada dengan menampilkan peringatan (Nuryati \& Widayanti, 2015). EHRs dengan sistem peringatan telah menjadi fokus dari beberapa dekade biomedis dan penelitian Informatika kesehatan serta penelitian layanan kesehatan (Bakken, 2019). Sebagian besar masalah keselamatan pasien terkait dengan kebutuhan tampilan peringatan yang tidak terpenuhi di EHRs dapat menyebabkan peningkatan potensi bahaya terhadap pasien (Meeks, Smith, Taylor, Sittig, Scott, \& Sing, 2014). Perkembangan EHRs diharapkan dapat meningkatkan keselamatan pasien.

Keselamatan Pasien dalam Peraturan Menteri Kesehatan RI nomor 11 tahun 2017 didefinisikan sebagai suatu sistem yang membuat asuhan terhadap pasien lebih aman, meliputi asesmen risiko, identifikasi dan pengelolaan risiko pasien, pelaporan dan analisis insiden, kemampuan belajar dari insiden dan tindaklanjutnya, serta implementasi solusi untuk meminimalkan timbulnya risiko dan mencegah terjadinya cedera yang disebabkan oleh kesalahan akibat melaksanakan suatu tindakan alau tidak mengambil tindakan yang seharusnya diambil. Insiden keselamatan pasien merupakan kejadian buruk yang terjadi pada pasien, kejadian nyaris cidera atau kondisi tidak aman yang berisiko mengancam keselamatan (Meeks, Takian, Sittig, Singh, \& Barber, 2014). Insiden keselamatan pasien sangat rentan terjadi termasuk pada pasien anak-anak.

Anak-anak merupakan merupakan populasi yang rentan dalam isu keselamatan pasien karena karakteristik fisik, masalah perkembangan, dan ketergantungan kepada orang dewasa, serta sistem kekebalan yang belum optimal (Ratwani et al., 2018). Oleh karena itu penulis tertarik untuk melakukan kajian tentang peranan EHRs terhadap keselamatan pasien di perawatan anak.

\section{Metode}

Metode yang digunakan adalah studi literatur dengan melakukan kajian artikel dan jurnal penelitian yang dicari melalui penelusuran database online yang terbit tahun 2014-2019. Adapun database online yang digunakan adalah ScienceDirect, OXFORD Academi, JSTOR, SAGE journals, ProQuest, Springer Link, Scopus, BioMed, Google Scholar, PubMed, American Journal of Health Sciences. Kata kunci yang digunakan adalah "electronic health record" OR "electronic medical record" AND "pediatric" AND "patient safety". Sebanyak 10 artikel yang dikaji, dan beberapa artikel lainnya sebagai sumber rujukan tambahan dalam pembahasan.

\section{Hasil Penelitian}

Hasil analisis menunjukan EHRs yang sudah dimodifikasi dengan menampilkan umpan balik tanda waspada berupa sistem peringatan dengan tampilan visual dapat meningkatkan komunikasi yang efektif antar tim kesehatan, memberikan peringatan dalam keamanan dan kewaspadaan obat, serta deteksi dini sepsis pada anak sehingga mendukung pengambilan keputusan untuk melakukan tindakan yang tepat untuk meningkatkan keselamatan pasien. Tabel 1.1 menggambarkan hasil kajian artikel secara umum. 


\section{Pembahasan}

Anak-anak merupakan populasi yang sangat rentan terhadap insiden keselamatan pasien (Ratwani et al., 2018). Keselamatan pasien anak berarti mencegah cedera pada anak yang disebabkan tidak hanya karena kecelakaan tetapi juga oleh sistem perawatan kesehatan (Mueller et al., 2019). Insiden keselamatan pasien yang menjadi perhatian pada anak-anak di antaranya yaitu dosis obat yang tidak tepat. Hal ini disebabkan karena pertumbuhan fisiologis anak memengaruhi dosis pengobatan, sehingga dokter harus melakukan perhitungan berdasarkan berat badan untuk setiap individu, yang dapat menyebabkan kesalahan perhitungan dosis yang dapat merugikan keselamatan pasien (Chaparro et al., 2017).

Beberapa hasil penelitian yang dianalis menunjukkan bahwa EHRs yang sudah dimodifikasi dapat menampilkan sistem peringatan secara visual memiliki banyak manfaat untuk meningkatkan keselamatan pasien di perawatan anak.

Salah satu sistem dalam EHRs yang dapat mendukung dalam program keselamatan pasien disebut Clinical Decision Support (CDS) dengan tampilan umpan balik berupa peringatan visual. EHRs dengan CDS dapat mengidentifikasi interaksi antar obat-obatan (Harper et al., 2014; Wright et al., 2019), dan efek samping obat yang merugikan (Bagattini, Karlsson, Rebane, \& Papapetrou, 2019), memberikan rekomendasi dosis yang aman untuk ginjal, dosis yang sesuai sesuai usia anak, peringatan terhadap adanya alergi obat, kelas obat, dan duplikat obat (Nanji et al., 2014; Simpao et al., 2015).

Sistem peringatan dalam EHRs terhadap obat ini sangat efektif untuk meningkatkan keselamatan pasien anak yang sangat rentan terhadap kesalahan dosis obat. Saiyed et al., (2019) menyatakan bahwa EHRs dengan peringatan tanda waspada terhadap obat memiliki potensi untuk meningkatkan kewaspadaan dan keselamatan pasien anak. CDS dari EHRs memberikan peringatan mengenai interaksi obat-obatan yang dapat merugikan pasien sehingga dapat ditindaklanjuti dengan segera (Manzi et al., 2017).

Selain dapat mengidentifikasi terhadap risiko kesalahan obat, EHRs juga dapat mengidentifikasi tanda-tanda awal masalah pada pasien anak melalui tanda peringatan yang menunjukan nilai pediatric early warning systems (PEWS). Seperti penjelasan Emmanuel dan Torres (2018) bahwa tanda peringatan yang menunjukan nilai PEWS pada EHRs dapat membantu perawat melakukan tindakan yang tepat sedini mungkin untuk mengatasi masalah pasien berisiko mengalami kondisi kritis dengan penanganan yang cepat termasuk pada anak dengan sepsis.

Sejalan dengan Paul et al., (2019) bahwa EHRs sebagai strategi dan mengotomatisasi tangkapan data dapat berfokus pada peningkatan terhadap pengenalan masalah pasien tepat waktu. EHRs dapat mengidentifikasi dan membantu memberikan interpretasi terhadap data pasien yang diinput ke dalam sistem algoritma skrining sepsis secara berkelanjutan dan otomatis dapat mengidentifikasi sepsis berat (Eisenberg et al., 2019), mempersingkat waktu dalam pengenalan sepsis pada pasien di perawatan anak (Boggs, 2019; Hackethal, 2018; Ruppel \& Liu, 2019). Dengan demikian EHRs dapat membantu perawat mengambil keputusan untuk melakukan tindakan dengan cepat.

Shelov et al., (2018) dalam penelitiannya menjelaskan alat CDS otomatis dalam EHRs, berupa peringatan dalam EHRs dalam format PICU Warning tool, untuk meningkatkan perhatian terhadap kondisi pasien di ruang PICU dapat berfungsi sangat efektif secara otomatis mengidentifikasi kondisi pasien yang berisiko memburuk.

Shelov juga menjelaskan bahwa hal ini mampu meningkatkan dua kali lipat kualitas intervensi keperawatan dan keselamatan pasien. Untuk itu sistem CDS berupa peringatan dalam EHRs yang terintegrasi dengan PEWS sangat penting dan dibutuhkan oleh perawat di perawatan anak. Saat ini sejauh pengetahuan penulis, EHRs di indonesia belum terintegrasi dengan PEWS. Hal ini dapat menjadi dasar pengembangan EHRs selanjutnya.

Beberapa hasil penelitian menunjukan bahwa EHRs dapat meningkatkan komunikasi efektif antar tim kesehatan serta menghindari tulisan yang tidak lengkap dan tidak terbaca sehingga dapat meningkatkan keselamtan pasien. Hoover (2017) menjelaskan bahwa EHRs dapat memberikan produksi catatan yang terbaca dengan jelas. Sejalan Panesar et al., (2016) yang menjelaskan bahwa kelengkapan catatan dalam sistem EHRs juga dapat 
memperbaiki sistem dokumentasi dan komunikasi efektif antar tim kesehatan sehingga dapat meningkatkan keselamatan pasien. Pendapat yang sama dari Lehmann et al., (2015) bahwa EHRs memberikan jaminan informasi yang akurat dan meminimalkan kesalahan sehingga mendukung pemberian perawatan kesehatan yang aman untuk anak-anak.

Panesar et al., (2016) dalam penelitiannya menunjukkan catatan SBAR dalam EHRs meningkat secara signifikan dan lebih lengkap dibandingkan dengan catatan kertas. Kelengkapan catatan SBAR ini pada akhirnya memperbaiki dokumentasi dan meningkatkan komunikasi efektif antar tim kesehatan di ruang PICU. Komunikasi yang efektif dapat meningkatkan keselamatan pasien.

Hal ini didukung oleh Field et al., (2018) bahwa EHRs dapat mendukung komunikasi yang efektif antar tim kesehatan sehingga dapat meningkatkan keselamatan pasien. Dalam hal ini pengembangan EHRs dapat dikembangkan secara terus menerus disesuaikan dengan kebutuhan program keselamatan pasien termasuk dalam rangka meningkatkan komunikasi yang efektif antar tim kesehatan.

Studi literatur ini memiliki kelebihan dan kelemahan. Artikel yang dianalisis merupakan artikel terbaru sehingga dapat dipertanggungjawabkan keilmuannya. Sedangkan penelitian dalam artikel yang dianalisis belum memenuhi 6 sasaran keselamatan pasien secara keseluruhan. Sehingga belum dapat diketahui bagaimana efektifitas peranan EHRs pada 6 sasaran keselamatan pasien yang sesuai dengan Standar Nasional Akreditasi Rumah Sakit.

\section{Kesimpulan}

Secara keseluruhan EHRs memiliki peranan yang posisit terhadap keselamatan pasien di perawatan anak. Terutama EHRs yang sudah dimodifikasi dengan menampilkan umpan balik berupa peringatan visual. Peranan EHRs ini terutama dalam mencegah terjadinya insiden keselamatan pasien akibat kesalahan obat, mampu mengidentifikasi kondisi pasien apabila terjadi penurunan, serta memberikan kemudahan dalam meningkatkan komunikasi yang efektif antar tim kesehatan.

Pengembangan EHRs di perawatan anak dapat terus ditingkatkan sesuai dengan kebutuhan standar keselamatan pasien.
EHRs dapat dimodifikasi agar dapat memberikan umpan balik sistem dalam tampilan peringatan visual yang memudahkan perawat dan tim kesehatan lainnya untuk mengidentifikasi risiko yang dapat membahayakan keselamatan pasien, sehingga dapat diantisipasi dan diatasi segera.

Selain itu pengembangan EHRs yang terintegrasi dengan PEWS, nilai kritis laboratorium dan hasil pemeriksaan kritis X-Ray dapat terus dikembangkan untuk menghindari data yang hilang serta meningkatkan komunikasi yang efektif dan memberikan kemudahan dalam pengambilan keputusan.

\section{Ucapan Terimakasih}

Penulis mengucapkan terima kasih yang sebesar-besarnya kepada Dr. Rr.Tutik Sri Hariyati, S.Kp., MARS Tuti Afriyani, S.Kep, M.Kep., Ns. La Ode Abd Rahman, S.Kep.,MBA., Ns. Sukihananto, S.Kep, M.Kep., rekan-rekan mahasiswa Program Magister Keperawatan Anak Fakultas Ilmu Keperawatan Universitas Indonesia angkatan 2019. serta seluruh komponen yang terlibat dalam penelitian ini, yang tidak dapat kami sebutkan satu persatu sehingga penelitian ini dapat diselesaikan.

\section{Daftar Pustaka}

Bagattini, F., Karlsson, I., Rebane, J., \& Papapetrou, P. (2019). A classification framework for exploiting sparse multivariate temporal features with application to adverse drug event detection in medical records. $B M C$ Medical Informatics and Decision Making, 19(1), 1-20. https://doi.org/10.1186/s12911-0180717-4

Bakken, S. (2019). Need for innovation in electronic health record-based medication alerts. 26(10), 901-902. https://doi.org/10.1093/jamia/ocz155

Boggs, W. (September, 17 2019). SepsisAlert System in the ED May Cut Racial Disparity in Pediatric Sepsis Recognition. Medscape. Diakses dari https://www.medscape.com/viewarticl e/918372 pada hari Jumat. 11 Oktober 2019, pukul 21.25 WIB.

Chaparro, J. D., Classen, D. C., Danforth, M., Stockwell, D. C., \& Longhurst, C. A. (2017). National trends in safety performance of electronic health record systems in children's hospitals. 
Journal of the American Medical Informatics Association, 24(2), 268274.

https://doi.org/10.1093/jamia/ocw134

Eisenberg, M., Madden, K., Christianson, J. R., Melendez, E., \& Harper, M. B. (2019). Performance of an Automated Screening Algorithm for Early Detection of Pediatric Severe Sepsis. Pediatric Critical Care Medicine, 1. https://doi.org/10.1097/pcc.000000000 0002101

Emmanuel, J., \& Torres, A. (2018). The Impact of Automated Electronic Surveillance of Electronic Medical Records on Pediatric Inpatient Care. Cureus, 10(10), 1-11. https://doi.org/10.7759/cureus.3395

Field, M., Fong, K., \& Shade, C. (2018). Use of Electronic Visibility Boards to Improve Patient Care Quality, Safety, and Flow on Inpatient Pediatric Acute Care Units. Journal of Pediatric Nursing, 41, 69-76. https://doi.org/10.1016/j.pedn.2018.01 .015

Hackethal, V. (Desember 11, 2018). EHR Alert Reduces Excess Cardiac Telemetry in Hospital. - Medscape diakses

dari https://www.medscape.com/viewa rticle/906384 pada hari Jumat, 11 Oktober 2019 Pukul 21.30 WIB.

Harper, M. B., Longhurst, C. A., McGuire, T. L., Tarrago, R., Desai, B. R., \& Patterson, A. (2014). Core drug-drug interaction alerts for inclusion in pediatric electronic health records with computerized prescriber order entry. Journal of Patient Safety, 10(1), 5963.

https://doi.org/10.1097/PTS.00000000 00000050

Hoover, R. (2017). Benefits of using an electronic health record. Nursing Critical Care, 12(1), 9-10. https://doi.org/10.1097/01.CCN.00005 $08631.93151 .8 \mathrm{~d}$

Jamshed, N., Ozair, F., Sharma, A., \& Aggarwal, P. (2015). Ethical issues in electronic health records: A general overview. Perspectives in Clinical Research, 6(2), 73. https://doi.org/10.4103/22293485.153997

King, J., Patel, V., Jamoom, E. W., \& Furukawa, M. F. (2014). Clinical benefits of electronic health record use: National findings. Health Services Research, 49(1 PART 2), 392-404. https://doi.org/10.1111/14756773.12135

Kirkendall, E. S., Kouril, M., Dexheimer, J. W., Courter, J. D., Hagedorn, P., Szczesniak, R., ... Spooner, S. A. (2017). Automated identification of antibiotic overdoses and adverse drug events via analysis of prescribing alerts and medication administration records. Journal of the American Medical Informatics Association, 24(2), 295-302. https://doi.org/10.1093/jamia/ocw086

Koch, V., Kuge, S., Geissbauer, R., \& Schrauf, S. (2014). Industry 4.0 Opportunities and challenges of the industrial internet. Strategy\& Formerly Booz \& Company, PwC, 13, $1-51$.

https://doi.org/10.1016/j.futures.2014. 12.002

Lehmann, C. U., Weinberg, S. T., Alexander, G. M., Beyer, E. L., Del Beccaro, M. A., Francis, A. B., ... Krams, L. (2015). Pediatric aspects of inpatient health information technology systems. Pediatrics, 135(3), e756-e768. https://doi.org/10.1542/peds.2014$\underline{4148}$

Manzi, S. F., Fusaro, V. A., Chadwick, L., Brownstein, C., Clinton, C., Mandl, K. D., ... Hawkins, J. B. (2017). Creating a scalable clinical pharmacogenomics service with automated interpretation and medical record result integration experience from a pediatric tertiary care facility. Journal of the American Medical Informatics Association, 24(1), 74-80. https://doi.org/10.1093/jamia/ocw052 Meeks, D. W., Smith, M. W., Taylor, L., Sittig, D. F., Scott, J. M., \& Sing, H. (2014). An Analysis of Electronic Health Record-Related patient Safety Concerns. J Am Med Inform Assoc, 21, 1053-1059.

https://doi.org/10.1136/amiajnl-2013002578

Meeks, D. W., Takian, A., Sittig, D. F., Singh, H., \& Barber, N. (2014). Exploring the sociotechnical intersection of patient safety and electronic health record implementation. Journal of the American Medical Informatics 
Association, 21(E2), 10-11. https://doi.org/10.1136/amiajnl-2013001762

Menkes RI. (2017). Peraturan Menteri Kesehatan Republik Indonesia Nomor 11 tahun 2017 tentang Keselamatan Pasien. Jakarta.

Mueller, B. U., Neuspiel, D. R., Stucky Fisher, E. R., Franklin, W., Adirim, C. T., Bundy, D. G., ... Schwalenstocker, E. (2019). Principles of pediatric patient safety: Reducing harm due to medical care. Pediatrics, 143(2). https://doi.org/10.1542/peds.20183649

Nanji, K. C., Slight, S. P., Seger, D. L., Cho, I., Fiskio, J. M., Redden, L. M., ... Bates, D. W. (2014). Overrides of medication-related clinical decision support alerts in outpatients. Journal of the American Medical Informatics Association, 21(3), 487-491. https://doi.org/10.1136/amiajnl-2013001813

Nuryati, \& Widayanti, N. A. ( 2015). Evaluasi Implementasi Sistem Electronic Health Record (EHR) Di Rumah Sakit Akademik Universitas Gadjah Mada. Jurnal Manajemen Informasi Kesehatan Indonesia, ISSN:2337-585X, Vol.3, No.1, Maret 2015, 17-30.

Panesar, R. S., Albert, B., Messina, C., \& Parker, M. (2016). The Effect of an Electronic SBAR Communication Tool on Documentation of Acute Events in the Pediatric Intensive Care Unit. American Journal of Medical Quality, 31(1), 64-68. https://doi.org/10.1177/106286061455 3263

Paul, R., Macias, C., Elliot, M., Wathen, B., Larsen, G., Chapman, L., ... Wake, T. (2019). A Quality Improvement Collaborative Improves Care for Pediatric Septic Shock *. Pediatrics, 141 (1 MeetingAbstract) 336 1-5.. https://doi.org/10.1542/peds.141.1_Me etingAbstract.336

Ratwani, R. M., Savage, E., Will, A., Fong, A., Karavite, D., Muthu, N., ... Rising, J. (2018). Identifying electronic health record usability and safety challenges in pediatric settings. Health Affairs, 37(11), 1752-1759. https://doi.org/10.1377/hlthaff.2018.06 99
Ruppel, H., \& Liu, V. (2019). To catch a killer: Electronic sepsis alert tools reaching a fever pitch? BMJ Quality and Safety, 693-696. https://doi.org/10.1136/bmjqs-2019009463

Saiyed, S. M., Davis, K. R., \& Kaelber, D. C. (2019). Differences, Opportunities, and Strategies in Drug Alert Optimization-Experiences of Two Different Integrated Health Care Systems. Applied Clinical Informatics, 10(5), 777-782. https://doi.org/10.1055/s-00391697596

Shelov, E., Muthu, N., Wolfe, H., Traynor, D., Craig, N., Bonafide, C., ... Dewan, M. (2018). Design and Implementation of a Pediatric ICU Acuity Scoring Tool as Clinical Decision Support. Applied Clinical Informatics, 9(3), 576-587. https://doi.org/10.1055/s0038-1667122

Simpao, A. F., Ahumada, L. M., Desai, B. R., Bonafide, C. P., Gávez, J. A., Rehman, M. A., ... Shelov, E. D. (2015). Optimization of drug-drug interaction alert rules in a pediatric hospital's electronic health record system using a visual analytics dashboard. Journal of the American Medical Informatics Association, 22(2), 361-369. https://doi.org/10.1136/amiajnl-2013002538

Wright, A., McEvoy, D. S., Aaron, S., McCoy, A. B., Amato, M. G., Kim, H., ... Sittig, D. F. (2019). Structured override reasons for drug-drug interaction alerts in electronic health records. Journal of the American Medical Informatics Association, 26(April), 934-942. https://doi.org/10.1093/jamia/ocz033 